\title{
Outcomes of adolescents treated involuntarily under the Canadian mental health act David Cawthorpe ${ }^{* 1,2}$ and TCR Wilkes ${ }^{3,4}$
}

\begin{abstract}
Address: ${ }^{1}$ The University of Calgary, Faculty of Medicine, Departments of Psychiatry and Community Health Sciences, 330 Hospital Drive NW, Calgary Alberta T2N 4N1, Canada, ${ }^{2}$ Calgary Health Region, Richmond Road Diagnostic Center, Room 4502, 1820 Richmond Road SW, Calgary Alberta T2T 5C7, Canada, ${ }^{3}$ The University of Calgary, Faculty of Medicine, Department of Psychiatry, 3330 Hospital Drive NW, Calgary Alberta T2N 4N1, Canada and ${ }^{4}$ Child and Adolescent Mental Health Program, 2888 Shaganappi Trail NW, Calgary Alberta T3B 6A8, Canada

* Corresponding author
\end{abstract}

from WPA Thematic Conference. Coercive Treatment in Psychiatry: A Comprehensive Review

Dresden, Germany. 6-8 June 2007

Published: 19 December 2007

BMC Psychiatry 2007, 7(Suppl I):S77 doi:10.1 |86/I47|-244X-7-SI-S77

This abstract is available from: http://www.biomedcentral.com/I47I-244X/7/SI/S77

(c) 2007 Cawthorpe and Wilkes; licensee BioMed Central Ltd.

\section{Background}

Restraint takes several forms. The effects on adolescents of the social form of constraint know as formal certification are considered wherein patient legal status is involuntary, compelling them to remain in a treatment setting for 30 days (renewable) under the Mental Health Act.

\section{Methods}

Annual data collected in the regional CAMHP information system from 2002-2006 ( $\mathrm{n}=21,107$ referrals) was used to compare clinical characteristics and functional outcomes of voluntary and involuntary patients with formal certification status under the Mental Health Act. Analyses included descriptive statistics, (e.g. clinical characteristis, population-based rates and frequencies), regression, logistic regression and Chi Square analysis, with graphical representation.

\section{Results}

Compared to those without status, those with certification status had on average $6(n=752)$ registrations system wide for those with status compared to $1(n=20,656)$ for system wide those without status. For those treated at the same level of inpatient or urgent service, an average of 6 registrations were observed $(n=390)$ for those with status compared to an average of 3 admissions $(n=1416)$ for those without status. Those treated at the same level of inpatient or urgent service with status were older and had significantly more comorbidity, greater urgency on admis- sion and longer lengths of stay. More than those without status, status patients more often were diagnosed with psychosis and more often had child protection status. Those with status were more functionally impaired on admission, but were comparable to those without status on discharge.

\section{Conclusion}

Formal certification appears to be used on a unique population of patients (involuntary) who require treatment and differ substantially from patients without formal status (voluntary). It appears that this legislative form of restraint does not impair the functional improvement of this population. 